\title{
La indigenización del mercado: el caso del intercambio de productos en las comunidades indígenas de Tarapacá en la Amazonía colombiana
}

\author{
Pablo De La Cruz
}

Colegio de la Frontera Sur, San Cristóbal de las Casas, México.

Email:pedelacruz@ecosur.edu.mx

\section{Eduardo Bello}

Colegio de la Frontera Sur, San Cristóbal de las Casas, México

Email: ebello@ecosur.mx

\section{Luis Eduardo Acosta}

Instituto Amazónico de Investigaciones Científicas Sinchi, Leticia, Colombia

Email: lacosta@sinchi.org.co

\section{Erín Estrada Lugo}

Colegio de la Frontera Sur, San Cristóbal de las Casas, México

Email: estrada@ecosur.mx

\section{GuillermoMontoya}

Colegio de la Frontera Sur, San Cristóbal de las Casas, México

Email: gmontoya@ecosur.mx

Resumen $^{1}$ : Se analizan las formas de intercambio de productos de familias indígenas habitantes del casco urbano de Tarapacá en la Amazonia colombiana, como una dialéctica entre las relaciones de reciprocidad de las economías indígenas y la influencia de las economías de mercado. Para eso, se reflexiona sobre la forma como las familias intercambian y comercian con productos de la agrobiodiversidad presente en chagras, ríos y selvas. El intercambio, como parte del sistema social, se regula por una dialéctica del valor entre las formas comunitarias y capitalistas, que atraviesa en mayor o menor grado las formas que la economía indígena ha tomado actualmente.

Palabras clave: Mercados, reciprocidad, intercambios, abundancia, amazonía colombiana. 


\title{
The indigenization of market: the case of product exchange in indigenous communities of Tarapacá in the Colombian Amazon
}

\begin{abstract}
The article analyzes the forms of products exchange amongst indigenous families who are residents of Tarapacá in the Colombian Amazon as a dialectic between reciprocity relationships of indigenous economies and the influence of market economies. For that, we reflect on how families exchange and trade with agro-biodiversity products in chagras, rivers and forests. As part of the social system, the exchange is regulated by a dialectic of value between the Community and capitalist forms, which in differing degrees is transversal to the forms that the indigenous economy has now taken.
\end{abstract}

Keywords: Markets, reciprocity, exchanges, abundance, colombian amazon.

\section{A indigenização do mercado: o caso do intercambio de produtos nas comunidades indígenas de Tarapacá na Amazônia colombiana}

Resumo: Se analisam as formas de intercambio de produtos de famílias indígenas habitantes da estrutura urbana de Tarapacá na Amazônia colombiana, como uma dialética entre as relaciones de reciprocidade das economias indígenas e a influencia das economias de mercado. Para isso, se reflexiona sobre a forma como as famílias intercambiam e comerciam com produtos da agro biodiversidade presente em chacras, rios e selvas. O intercambio, como parte do sistema social, regula-se por uma dialética do valor entre as formas comunitárias e capitalistas, que perpassa em maior ou menor grau as formas que a economia indígena tem adquirido atualmente.

Palavras-chave: Mercados, reciprocidade, intercâmbios, abundancia, amazônia colombiana.

\section{Introducción}

Las formas de intercambio de los pueblos indígenas han sido descritas como sistemas basados en la abundancia, en contraposición a los sistemas de la economía de mercado basados en el principio de escasez(Sahlins, 1983). Estas diferencias axiológicas representadas en la contraposición entre la ideología capitalista de occidente, y las diversas formas de intercambio de los pueblos originarios, se ha trazado en los pueblos indígenas amazónicos con mayor fuerza desde finales del siglo XIX cuando inician los diferentes ciclos de la economía extractiva(Zárate Botía, 2001).Desde entonces, diversos pueblos indígenas fueron reducidos a centros poblados, forzados a ser mano de obra, y a hacer parte de una política de asimilación que se promovió desde los gobiernos nacionales. Este cambio en las formas de vida llevó a muchos indígenas a depender de productos manufacturados, y hacer parte de un sistema económico más allá de las fronteras bioculturales de los territorios que habitaban. 
La actual forma que han adoptado los pueblos y comunidades amazónicas para apropiarse de espacios urbanos y ejercer actividades de comercio e intercambio, es descrito por varios autores como una estrategia mixta de las comunidades para adaptarse a sistemas de intercambio que responden a una lógica de redistribución y reciprocidad, a la vez que se orientan hacia la acumulación y la ganancia. La producción de las chagras hacia el mercado, la reducción de espacio para sembrar, ha hecho que los sistemas productivos indígenas se modifiquen en abundancia y diversidad de especies sembradas ya que los criterios de siembra varían en parte por la demanda del mercado local(Eloy, 2008; Fontaine, 2002; Freire, 2014; Mora de Jaramillo, 2012; Pinton, 2003; Trujillo Osorio, 2008; Yagüe, 2013).

En este artículo se analizan los sistemas de intercambio de los pueblos indígenas de la región de Tarapacá, al sur de la Amazonía colombiana. En Tarapacá, las familiaspractican la agricultura de roza tumba y quema, se sustentan en gran parte gracias a un sistema productivo, de intercambio y autoconsumo que integra los ciclos agroecológicos y climáticos a las relaciones de reciprocidad. Estos sistemas han sido interrumpidos en gran parte por las economías extractivas que han operado históricamente en la región, y que han sometido a la población indígena a economías de endeude, pérdida de agrobiodiversidad, y desestructuración de sus modos tradicionales de vida, poniendo en peligro la transmisión de estos saberes(Acosta, 2013).Para eso se presentan resultados de una Investigación Acción Participativa en Tarapacá en la cual han participado las organizaciones indígenas, de mujeres y que dan una idea de la forma como las familias intercambian y comercian con productos de la agrobiodiversidad presente en chagras, ríos y selvas. La acción interinstitucional se ha enfocado a la promoción de Ferias de Chagras, como espacios urbanos para el intercambio y venta de productos,y una forma de vincular la producción en chagras a los circuitos locales de comercialización.

Los resultados se analizan en relación a los aportes teóricos de la antropología económica para la comprensión de las economías tradicionales y los mercados locales. Esta reflexión, nos permiteexplicar la lógica del valor en economías indígenas inmersas en contextos multiculturales.Y entender los sistemas de intercambio de los pueblos indígenas amazónicos como parte de un sistema social que se regula por una dialéctica del valor entre las formas comunitarias y capitalistas que atraviesan, en mayor o menor grado, las formas que la economía indígena ha tomado actualmente.

En términos de Gudeman (2001), como una dialéctica comunidadmercado condos esferas de intercambio, uno comunitario y otro comercial, donde los objetos y personas cambian de valor a medida que cambian las esferas.Al final se discute la tesis que las economías indígenas basadas en sistema productivo de chagras y en relaciones de reciprocidad pueden presentar formas novedosas de adaptación a los mercados locales, donde antes de hablar de mercados capitalistas podemos referirnos a procesos de construcción de mercados indígenas, inspirados en la famosa metáfora de Sahlins sobre la indigenización de la modernidad. 


\section{Aportes desde la antropología económica}

Sahlins y Polanyi definieron la acción económica en sociedades indígenas como parte de un sistema social basado en la reciprocidad y la centralidad (Polanyi, 1989; Sahlins, 1983). Presentaron la idea de intercambio (Siegal, 1965) y de mercado, como un constructo hipotético que puede dar luces sobre la forma como se concibe la acción económica, y cómo se regula a través de las relaciones sociales en las sociedades más simples y no monetarizadas (Nash, 1967).

Para Sahlins (1983) el intercambio posee una lógica propia del valor, el tipo de transacciones económicas son de dos tipos. En primer lugar, están los movimientos «vice-versa» entre dos partes conocidos más comúnmente como reciprocidad. Segundo, los movimientos centralizados: recolección por parte de los miembros de un grupo, a menudo bajo un solo mando y redistribución dentro de este grupo.

Las discusiones sobre la reciprocidad incluyen su continuo contraste con las relaciones de mercado y el punto de vista moral involucrado. Para Sahlins (1999) a pesar de las famosas declaraciones de Marx y Simmel acerca de los efectos destructivos de los mercados y el dinero en la comunidad, una de las grandes sorpresas de "capitalismo tardío" es que las culturas "tradicionales" no son necesariamente incompatibles con ella ni vulnerables a ella.

ParaSahlins (1999), muchos etnógrafos que escribieron sobre pueblos aborígenes desde el siglo XIX y el XX, y que pronosticaron su desaparición por la inminente asimilación a la vida urbana, a los valores del progreso, y el desarrollo, afortunadamente estaban equivocados. Los pueblos indígenas se modernizan, y la modernidad se indigeniza, y este movimiento de retorno que se da en la sociedad global, es la clave para pensar que las culturas no se destruyen sino que se reorganizan en formas emergentes.

Pensar en una diversidad cultural que es devorada por la uniformidad del capitalismo y la globalización, es una imagen simplista, que da cuenta de aspectos que juzgamos desde nuestros propios valores. Sobre todo, cuando un complemento de la nueva era global es la autoconciencia de la "cultura", como un valor para ser vivido y defendido, y que rompe con las ideas monosilábicas de los Terceros y Cuartos mundos. La autoconciencia de la "cultura" significa la demanda de los pueblos por su propio espacio dentro del orden cultural mundial. Esto, según Sahlins, significa más a menudo un deseo de indigenizarse. El proyecto es la indigenización de la modernidad (Sahlins, 1999).

"Unificado por la expansión del capitalismo occidental durante los últimos siglos, el mundo también está siendo re-diversificado por adaptaciones indígenas a la gran globalización. En alguna medida, la homogeneidad global y la diferenciación local se han desarrollado conjuntamente, el último como una respuesta al primero, en nombre 
de una nativa autonomía cultural. La nueva organización planetaria ha sido descrita como "una Cultura de culturas", un sistema cultural del mundo formado por diversas formas de vida” (Sahlins, 1999:10).

Según Graeber (2001), el problema con la reciprocidad es siempre el de encontrar condiciones viables de comparación. Los términos usados por Mauss, como la "prestación total”, "el regalo", "reciprocidad”, sirvieron para formular puntos de vista morales acerca de la lógica del mercado, pero como instrumentos contundentes de comparación intercultural son términos confusos que pueden significar cualquier cosa. Sin embargo, como formas de acercarnos a las economías indígenas como sistemas en acelerado cambio, la reciprocidad, el intercambio y la centralidad, son conceptos que ayudan a comprender la adaptación de las economíasen los pueblos indígenas de la Amazonía. La probabilidad de que respondan a lógicas propias, indígenas, tradicionales, está dada en gran medida por el grado y forma de integración de las comunidades con las economías de mercado y los Estados nacionales(De La Cruz, 2010). Para esto, es importante revisar los antecedentes que refieren a indígenas que viven en contextos amazónicos urbanos, sus diferentes estrategias para participar de los intercambios y venta directa de productos, y dar cuenta de las transformaciones en sus sistemas de conocimiento tradicional.

\section{Adaptaciones al mercado en la Amazonía suramericana}

Estudios recientes en la Amazonia suramericana indagan la relación entre mercados locales y prácticas tradicionales, y específicamente, cómo se manifiesta un intercambio o comercio de productos de la agrobiodiversidad. Establecen puntos de vista sobre valoración de alimentos tradicionales en procesos de urbanización (de Robert \& van Helthem, 2008) y las adaptaciones culturales al comercio, producción de excedentes y sus consecuencias en los conocimientos tradicionales (Fontaine, 2002; Acosta et al., 2011, Hernández et al., 2010) humanos donde las diferentes condiciones de urbanización humanos donde las diferentes condiciones de urbanización humanos donde las diferentes condiciones de urbanización (Arcila, 2011), y el grado de integración de las comunidades indígenas a las economías de mercado establecen ciertas tendencias para la consolidación de estrategias alimentarias locales que incluyan a la producción indígena, y su articulación con canales de intercambio y comercio (Eloy \& Le Tourneau, 2009; Eloy, 2008). Y explican cómo las redes alimentarias, los mercados locales o indígenas, son parte de una estrategia para el sostenimiento de una diversidad alimentaria basada en los conocimientos tradicionales asociados a la agrobiodiversidad.

Según Castro (2009) y Peña-Venegas et al., (2009), los sistemas productivos indígenas se han transformado por la transición de la familia tradicional hacia familias monoparentales y extensas, que ha debilitado las relaciones y vínculos de parentesco, "lo que a su vez ha provocado que las prácticas productivas tradicionales se articulen cada vez más con las activi- 
dades del mercado para suplir esas nuevas demandas” (p. 60). Otro factor que restringe la reproducción de los sistemas productivos tradicionales es la educación formal, que afecta la disponibilidad de los más jóvenes para participar del trabajo de la chagra (Gasché, 2010). Los modelos metodológicos y diseños de contenidos son por lo general descontextualizados del medio amazónico y no incorporan los mecanismos tradicionales de apropiación de conocimientos (De La Cruz, 2013). Esta situación es observada por Gasché (2010) para quien los maestros de las escuelas no toman en cuenta el hecho de que el modo de vida indígena requiere sus propias competencias y habilidades.

En cuanto al consumo de productos manufacturados, los datos de Tarapacá no difieren mucho de Puerto Nariño, La Chorrera, La Pedrera y Leticia (Peña-Venegas, Mazorra, Acosta and Pérez, 2009; Acosta et al., 2011; Yagüe 2013; Fontaine, 2002). Según Hernández et al., (2010), el uso de productos empacados viene reemplazando el consumo de alimentos tradicionales. Las gaseosas y refrescos saborizados ya son parte de la dieta de la gran mayoría de tarapaqueños, quienes por facilidad o status, lo prefieren a un jugo natural, el cual implica traer la fruta de la chagra o adquirirlo en las pocas tiendas disponibles.

Este continuo reemplazo de alimentos de la chagra por otros de origen agroindustrial genera mayor dependencia alimentaria y debilita las prácticas agrícolas tradicionales (Peña-Venegas, Mazorra, Acosta and Pérez, 2009; Acosta et al., 2011). El bajo acceso de los chagreros a los canales de comercialización se evidencia en la no existencia de una plaza de mercado en Tarapacá, el casi nulo uso de animales de carga para traer productos de las chagras y la desmotivación de los más jóvenes a participar de las actividades agrícolas (Hernández et al., 2010). En este punto, pensar en un futuro fortalecimiento de cadenas de valor con productos tradicionales como la fariña, el almidón, pulpas, entre otros, apunta a integrar un mercado interno para consumo local, generando vías de comercialización directa para el productor como una “plaza de mercado”, o lo que se ha llamado en Tarapacá como "mercados de abundancia” (Sinchi, 2014). En ese sentido, resaltan los aportes de Yagüe (2013) quien analiza los mercados indígenas instalados en Leticia como una manera de traer el mundo rural hacia lo urbano, donde la mayoría de compradores son indígenas y es importante la cantidad y diversidad de alimentos que se pueden encontrar.

\section{Metodología}

Se presenta una etnografía que analiza información proveniente de métodos cualitativos como encuestas semiestructuradas y conversatorios, con algunos datos cuantitativos obtenidos a partir de diarios de consumo, encuestas, e información secundaria del Instituto Amazónico de Investigaciones Científicas Sinchi y las organizaciones locales Asociación de Autoridades Indígenas Tradicionales de Tarapacá Amazonas, ASOAINTAM; Cabildo Indígena Mayor de Tarapacá, CIMTAR; y Asociación de Mujeres 
Comunitarias de Tarapacá, ASMUCOTAR. También se utilizó un juego de rol diseñado específicamente para esta investigación y que permitió simular algunas estrategias que las personas realizan para obtener e intercambiar alimentos. Esta metodología es una forma de hacer etnografía experimental, donde no solo es importante conocer desde el punto de vista objetivo las estrategias de los jugadores, sino documentar las condiciones de posibilidad en la que se dieron. Esto incluye conocer tanto las restricciones y posibilidades del juego como las epistemes de quienes lo juegan.

Partimos de la hipótesis que la participación de las familias indígenas en el intercambio y comercialización de productos revaloriza ciertos conocimientos tradicionales en su interacción con las estructuras sociales, y económicas, en la cual están inmersas las comunidades indígenas, por lo tanto, la búsqueda de canales de comercialización de los productos tradicionales representa para las familias una forma novedosa de adaptarse a los cambios socioeconómicos. Se midió la participación de las comunidades indígenas en el intercambio y comercialización local de productos de la agrobiodiversidad, tomando como variables la venta directa e intercambio de productos, venta e intercambio con intermediarios, y participación en ferias. A partir de esta información se analizan las representaciones sociales de las familias sobre la forma y lugar de adquisición de productos locales, distribución según forma de adquisición, comercializadores, venta y destino de productos de la chagra, productos de la chagra comercializados, participación en mingas, y Ferias de Chagras.

\section{Conseguir la comida en Tarapacá}

Para los pueblos indígenas de la Amazonía la alimentación está basada en la agricultura de roza tumba y quema. Se abren chagras de no más de dos hectáreas, se siembra yuca, plátano, piña (Bromeliaceae), pimentón (Capsicum), coca (Erythroxylum coca), frutales ${ }^{2}$. Las chagras se trabajan por lo general bajo el sistema rotativo de minga, lo que quiere decir que el alimento de la chagra de una familia lo obtiene gracias al intercambio de trabajo. El papel de las mingas es fundamental en la vida de las familias y las comunidades. Es como la relación con la selva con la que se forma un todo, se reconocen los efectos mutuos y la mediación cultural facilita esta relación de largo plazo. Entre familias la minga está presente en las distintas facetas de la vida, en el disfrute del paisaje, en el trabajo, en los intercambios. La vida no está separada en producción, comercialización, recreación, la minga es una de las formas para mantener la vida como un todo.

Cuando llegan las cosechas, abundancia de pescado, o cacería, se da el proceso de transformación de algunos alimentos como el tucupí (caldo de color amarillo extraído de raíz de la yuca brava), la fariña (yuca rayada y tostada), el casabe (torta de yuca), el juare (envuelto de yuca, Manihot esculenta), pescado y carnes ahumadas, pulpas de frutas, entre otros. A pesar de la continuidad de los sistemas de chagras y las prácticas que regulan la transformación y circulación de alimentos por relaciones de reci- 
procidad, en Tarapacá, según la Figura 1, la mayor cantidad de productos locales que se adquieren son a cambio de dinero. Y más de la mitad de los productos que compran lo hacen en tiendas locales de comerciantes (Figura 2).

Figura 1: Distribución de productos locales consumidos por familia según forma de adquisición.

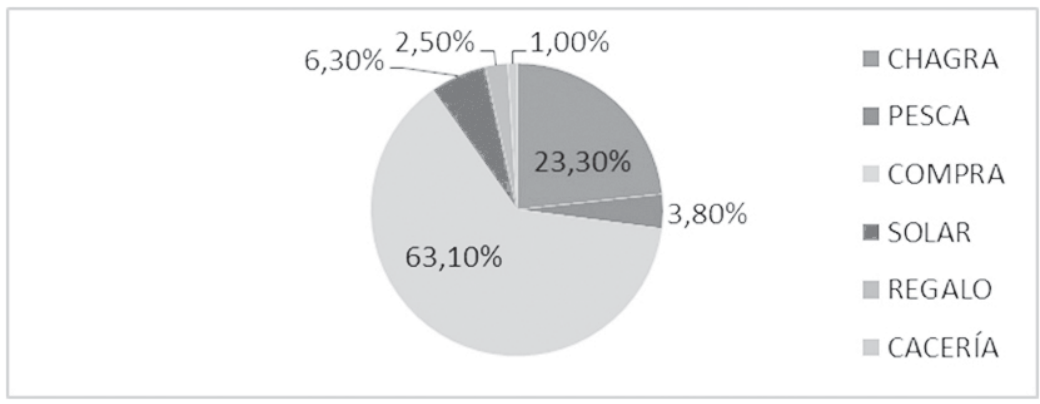

Fuente:Diario de consumo, Tarapacá. 2015.

Figura 2 Comercializadores de productos locales en Tarapacá.

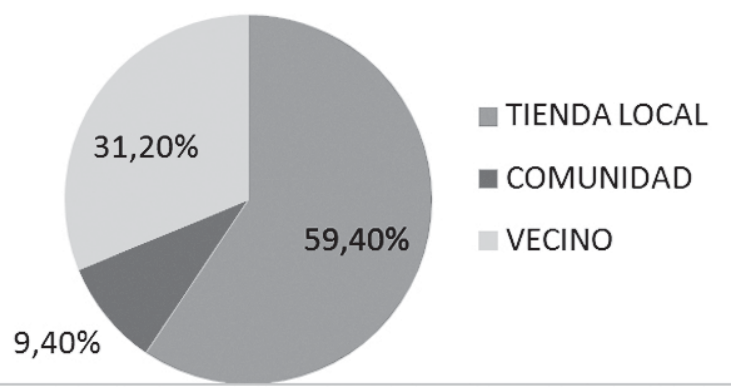

Fuente: Diario de consumo. Tarapacá 2015.

Los hábitos de consumo presentes en las cabeceras corregimentales del Departamento del Amazonas son un reflejo del acelerado cambio en las relaciones de reciprocidad por estructuras de mercado que han transformado las sociedades indígenas. Para Tarapacá, según el Sinchi (2014), los hábitos de consumo y dieta diaria están comprendidos por alrededor de 61 productos locales. El producto más demandado o consumido es la yuca con el $80 \%$, seguido del plátano con el $75 \%$, la fariña $65 \%$, piña $50 \%$, casabe $45 \%$, ñame $30 \%$. Son 29 clases de productos los más comprados en las 
tiendas y el que tiene mayor demanda es el arroz con un 75\%. Mientras los primeros son producto de un proceso de apropiación de la agrobiodiversidad local que se practica desde hace miles de años, regulado por los ciclos agroecológicos y culturales, los productos agroindustriales, como el arroz y el azucar, se obtienen por medio de la venta, o trueque.

Históricamente, en la Amazonía colombiana, el ingreso del dinero como medio de cambio está asociada a las economías de endeude (Rincón, 2005) y migraciones de colonos que han tenido presencia histórica en la región desde finales del siglo XIX (Arcila, 2011), además del proceso de asimilación de muchos indígenas a los estados nacionales. Según el líder indígena de ASOAINTAM Harold Rincón, la entrada del dinero como forma de intercambio fue precedida por el trueque que hacían las comunidades de Tarapacá con comerciantes y militares, razón por la cual se empezó a transformar las necesidades de los indígenas:

"la base militar y los comerciantes empezaron a hacer ese ejercicio de cambio de productos, ellos daban todos productos elaborados, yo me pregunto qué hacían los paisanos con lo que intercambiaban, con el frijol, con la leche, con la panela...pues se lo comían, eso antes no era un problema, incluso los mismos paisanos no pensaron que eso podría maximizar un problema de autodeterminación que tiene que ver con la soberanía alimentaria, decidir qué es lo que quiero comer” (Conversatorio ASOAINTAM, 2015).

Esta pérdida de autonomía en cuanto a la alimentación de las comunidades indígenas está asociada también a otros problemas de tipo estructural que se presentan en las familias, y que Peña-Venegas et. al., (2009) describen como la transición de la familia tradicional hacia familias monoparentales y extensas, que ha debilitado las relaciones y vínculos de parentesco. Esta situación ha provocado que las prácticas productivas tradicionales se articulen cada vez más con las actividades del mercado para suplir nuevas demandas, cuya satisfacción depende del acopio de ingresos monetarios.

\section{Las mingas, la redistribución y la reciprocidad}

La economía del regalo (Graeber, 2012) es parte de un proceso de redistribución por reciprocidad, que se manifiesta en la Amazonía cuando la gente organiza mingas. El significado y la funcionalidad de la minga se expresa en frases como "si yo participo con ellos, ellos participan conmigo" (Celina Tello); como una forma de colaboración e intercambio, "se reparte algo de la chagra, colinos, semillas” (Trinidad Polanía). La minga es una responsabilidad colectiva e individual, funciona porque media un compromiso, es la confianza, la credibilidad de la persona, su identidad lo que está en juego (Hernández et al., 2010). La alta frecuencia de mingas sugiere una constante redistribución de productos por reciprocidad. 
La reciprocidad se mantiene principalmente dentro de la familia nuclear, esa reciprocidad sin embargo puede ser desplazada hacia otros grupos sociales como la comunidad y la asociación que pueden, o no, coincidir con la misma familia. La creciente importancia de las organizaciones comunitarias y asociativas suplen la fuerza laboral que no les pueden proveer sus mismas familias, porque los jóvenes y niños van diariamente al colegio, o porque en el casco urbano, a diferencia de las comunidades, las afinidades y empatías no obedecen necesariamente a las familiares sino a otro tipo de vínculos de tipo comunitario, asociativo y hasta gremial.

La minga genera la capacidad de vivir con los otros, de aceptarse y sentirse parte de los otros, es una oportunidad de aprender, de obtener conocimientos. Estos aspectos de aprendizaje, sociales y económicos son factores determinantes a la hora de comparar los motivos que llevan a las familias a decidir si dan sus productos a parientes y amigos, o si prefieren venderlos. Más aún, dan cuenta de unared (o una red de redes) que integra dimensiones económica, social, y de conocimientos, y que también aplica a la esfera del intercambio y la comercialización, esto explica en parte porque en Tarapacá aún no se vive como una necesidad contar con un mercado permanente.

Sin embargo, cada vez estas redes y relaciones que se reproducen por medio de mingas para conseguir la comida y transmitir conocimientos se interrumpen por la creciente dependencia de las familias con el mercado laboral y la alimentación agroindustrial (Acosta, 2011; PeñaVenegas 2009). Por ejemplo para Harold Rincón, líder indígena de ASOAINTAM, la reciprocidad, economía del don:

"ya no es del todo cierto que sea cotidiano. Intercambio, trueque, es cuando tú vas donde un compañero a ayudarle a una chagra y te regaló un racimo de plátano por ayudarle a trabajar. La cacería es para el sustento familiar, pero también genera ganancias, ya no es un intercambio de producto a producto, entonces ya no se dan esos ejercicios de que te cambio una sarta de pescado por un gajo de plátano, sino tiene 4000 pesos pues no le doy su pescado y punto, porque ese pescado tiene esa intencionalidad de que se necesita el dinero. Pero hay otros momentos que son más centrados en las condiciones de las familias, de los núcleos familiares, como están configurados, como son esas redes que tejen las familias que practican un intercambio básico, eso tiene que ver con una afinidad, estamos hablando de consanguinidad, porque es el suegro, el cuñao, compadre. Se da intercambio cuando tengo danta y a mi ahijado voy a mandarle dos kilos y no voy a decirle, bueno, ya te mande estos dos kilos ahora regrésame algo, no, él después mató un puerco y me va a regalar la cabeza, eso se da en los círculos familiares, (Conversatorio ASOAINTAM, 2015).

Este desplazamiento de las centralidades basadas en relaciones 
de reciprocidad hacia esferas de mercado se refleja en los intercambios de semillas. Es posible afirmar que las semillas que se siembran en la chagra son producto de un intercambio cara a cara, es una práctica tradicional que se ha transformado al ritmo del cambio cultural. Según los relatos de los abuelos, el intercambio de semillas era una actividad prácticamente cotidiana, que se acentuaba durante los bailes y fiestas, cuando la abundancia de alguna especie permitía repartir a los diferentes clanes las semillas (De La Cruz, 2012), tal como lo narra el abuelo Jaime Yágenes:

“el intercambio de ellos era en las fiestas, los nonuyas hacían sus fiestas, invitaban a los Uitotos, los Boras y hay intercambiaban, si era fiesta de suko pues ellos llevaban carne, si era baile de charapa traían todo lo que es charapa, pescado y todo eso. Y entonces llega la otra colonización con el intercambio de pieles y mercancía, y hay ellos se apoderan de esas otras cosas como el plátano, yuca, todo lo que hay dentro de la chagra ellos ya le cambiaban por el machete, el hacha" (Conversatorio ASOAINTAM, 2015).

En los últimos años son muy pocos los intercambios de semillas

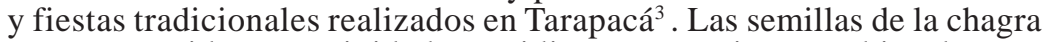
son conseguidas en actividades cotidianas, como intercambios durante las mingas, y a veces hasta compradas, es una actividad que se da sobre relaciones vecinales, de parentesco, amistad. Los cambios socioeconómicos en las relaciones de intercambio en Tarapacá hacia prácticas occidentales han erosionado fuertemente los eventos rituales y las fiestas de cosecha, momentos muy importantes para la sostenibilidad del sistema de chagras. Como consecuencia, y según datos obtenidos por el Sinchi (2014), hoy en día escasean las semillas y productos que antes si se tenían (De La Cruz, 2012). Esta situación coincide a lo encontrado por Fontaine (2002) en La Pedrera donde cada vez se realizan menos fiestas tradicionales.

\section{Las estrategias de intercambios de productos: entre la reciprocidad y el mercado}

En Tarapacá el 85\% de las familias encuestadas comercializan algún producto de la chagra. A pesar de la importancia señalada para el comercio de productos en Tarapacá (Figura 3), para muchas familias regalar un racimo de plátano es una opción más provechosa que tratar de venderlo. El valor de un producto en una economía donde los excedentes no es un factor que prevalece sobre las relaciones sociales explica porque muchas veces unas personas prefieren regalar, y no vender. 


\section{Figura 3 Lugar de adquisición de productos locales comercializados}

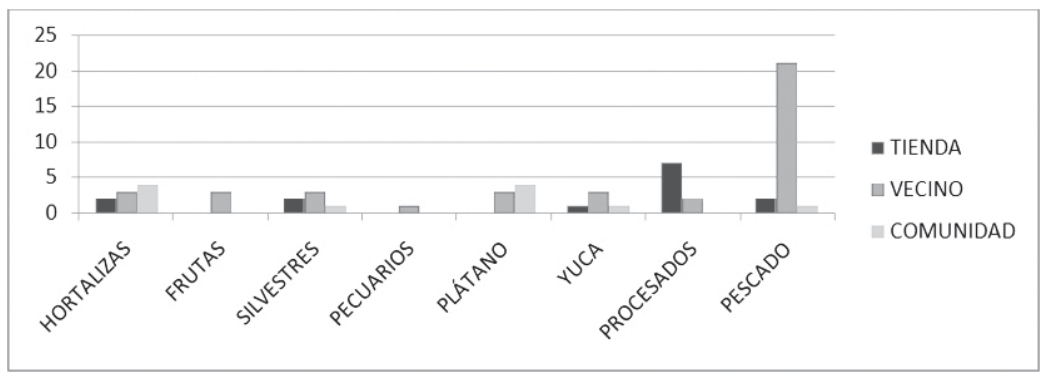

Fuente: Diarios de consumo, Tarapacá 2015.

El objetivo principal del sistema de chagras no es la comercialización, en una lógica que sugiere que no todo se puede cosechar para provecho de las personas, ni todos los productos son para vender. Esta lógica está marcada por la presencia de dos límites: el primero la temporalidad de la cosecha, y el segundo la idea de la suficiencia, o lo que es lo mismo, de la satisfacción. Si observamos la forma de trabajar una chagra, en la época de cosecha de varias especies, rara vez las familias lo cosechan todo. Prefieren llevar un poco de cada cosa, quizá de lo más necesario, las razones pueden ser que solo se puede llevar lo que la familia pueda cargar (no se dispone de animales, ni existen carreteras), muchos productos son para consumo en la misma chagra, hay que dejarle a los animales y algunos dicen, de manera jocosa, que hasta para los ladrones. Así, el límite de las cosechas difiere de un sistema de comercialización de productos bajo reglas estandarizadas de mercado. Es imposible llegar a una medida absoluta de la suficiencia, pero lo que si podemos pensar es que la suficiencia está estrechamente asociada al principio de abundancia ${ }^{4}$ (Acosta, 2013), que se opone al principio de escasez en la economía de mercado (Sahlins, 1983). Cuando algo es suficiente, lo es no solo para la familia o el grupo que siembra una chagra, sino para el sistema de relaciones en el cual se vive.

Otro motivo que explica por qué los sistemas de chagras no se orientan a un mercado estandarizado, son las relaciones afectivas que los agricultores tienen con su chagra. En este caso, el sentido apunta a una relación ontológica específica, la chagra como una extensión del "ser" de las relaciones familiares y comunitarias, relación que refleja la permanencia (Giraldo, 2013) de las relaciones que hacen posible la chagra. En las cosmogonías indígenas de la Amazonía, las interacciones ecológicas de las especies de la chagra y el bosque se asumen dentro de un orden del mundo, o en otras palabras, como parte de una cosmogénesis (Davis, 2009). De este modo se funda un tipo de relación afectiva que proyecta y muestra de quien es la chagra, quien es su dueño. La chagra que no está sembrada no tiene dueño, la chagra que esta cuidada, limpia, repre- 
senta el estatus mismo de la familia que la maneja, su lugar en la comunidad. Así como los ciclos de siembra y cosecha de las diferentes especies tienen sus tiempos, así mismo es el manejo general de las chagras. En este sentido, para una familia indígena, no tiene sentido hacer dos chagras al mismo tiempo.

A pesar de la permanencia de esta relación de las familias con el sistema de chagras, no podemos decir que su productividad se ha mantenido separada de las necesidades de un mercado local, sino antes bien la chagra como principal abastecedora de alimentos de la misma familia que la trabaja, también deja excedentes para la venta. Para las familias indígenas de Tarapacá, la chagra es parte de una estrategia de subsistencia que se conjuga con la cacería, la pesca y la recolección. Y aunque parte de estos productos también se usan para el comercio local, su propósito fundamental sigue siendo el abastecimiento familiar y comunitario (De La Cruz Nassar, 2015). En el momento que una actividad como la pesca o la agricultura se hace exclusiva para la venta, se esta favoreciendo una especialización hacia la comercialización, en detrimento del autoabastecimiento, y por lo tanto de la abundancia.

Los comerciantes son quienes por lo general le compran a los productores, estos se quedan con la mayor ganancia, dado que no invierten trabajo directamente, y hacen de intermediarios. Para muchas familias indígenas, no contar con el capital para almacenar y transportar los productos favorece a los comerciantes que cuentan con la infraestructura para almacenar comida, por lo tanto, las pocas alternativas que se tienen para comercializar productos de la chagra hacen que esta sea una actividad poco atractiva.

Dado que el puerto es el lugar de llegada de los pescadores resulta relativamente fácil comprar pescado. Los alimentos de la chagra, en cambio, son más difíciles de conseguir ya que hay que hacerlo por entre las casas, preguntando entre conocidos y amigos, no siempre con la certeza de conseguirlos. La venta de productos (Figura 4) es una actividad que funciona como una red vecinal, en una dialéctica comunidad-mercado (Gudeman, 2001), por ejemplo quienes tienen restaurantes en el pueblo cuentan con esas redes para conseguir los alimentos. Otra alternativa que se ha generado frente a las temporadas de frutas, ha sido la comercialización de pulpas y mermeladas por parte de organizaciones como ASMUCOTAR. Esta asociación compra frutas como copoazu, camu camu, piña y lulo para producir pulpas y mermeladas, el destino de esos productos esta principalmente en Bogotá, aunque ya cuentan con un mercado local y regional cada vez más importante ${ }^{5}$. 
Figura 4 Forma de adquisición de productos locales.

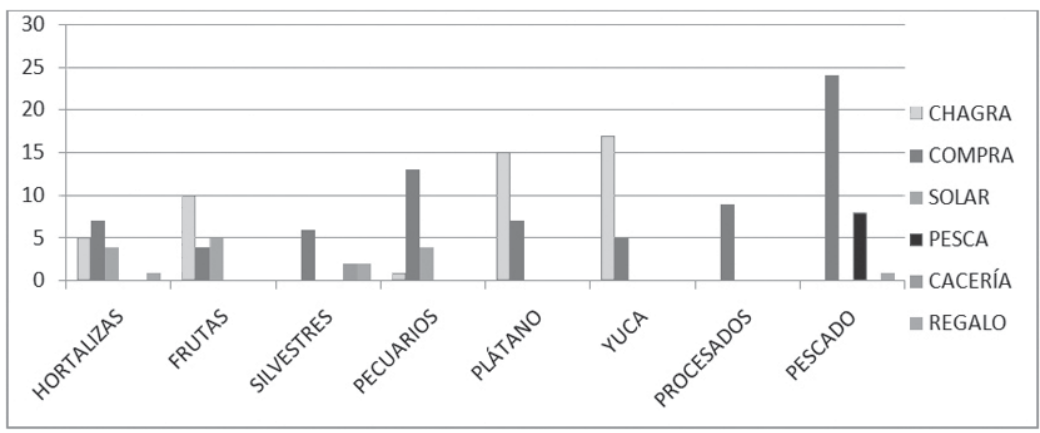

Fuente: Diarios de consumo, Tarapacá 2015.

\section{La indigenización del mercado}

Para las comunidades indígenas que habitan el casco urbano, la necesidad de acceso a bienes y servicios los ha llevado a combinar sus prácticas tradicionales de subsistencia con otras que les representen ingresos, las estrategias para acceder a esto van desde emplearse, participar en actividades extractivas, abrir negocios y comercializar productos de las chagras y solares (Hernández et al., 2010). En el casco urbano de Tarapacá no existe un espacio fijo dedicado al acopio, comercio e intercambio de productos, las personas que ejercen esta actividad lo hacen desde la puerta de sus casas, algunos caminan el pueblo ofreciendo productos, o les venden a tiendas y restaurantes.

Ante esta situación, desde la cooperación entre organizaciones indígenas, de mujeres y el Instituto Sinchi se ha planteado la necesidad de generar mecanismos que vinculen las economías tradicionales a los espacios urbanos por medio de Ferias de Chagras. Para las organizaciones locales e instituciones, impulsar dentro de la comunidad espacios propicios para el intercambio de productos es una estrategia para extender los sistemas productivos locales más allá de los ámbitos tradicionales, como una práctica que venga a posicionarse dentro de una esfera de intercambio de bienes y servicios al interior de la comunidad. Sobre esta vía es posible plantear nuevas propuestas que ayuden a fortalecer y dinamizar su importancia dentro de la esfera local y regional (De La Cruz, 2012).

Los motivos de las comunidades indígenas de participar en intercambios comerciales a nivel local o regional no se da únicamente por participar de mejores beneficios comerciales, sino en sus intereses está reivindicar procesos organizativos locales, mingas y expresiones culturales que dan el sustento político a esta centralidad y sobre todo, a revalorar los 
conocimientos tradicionales en un contexto interpolado por lógicas capitalistas e indígenas de mercado.

La búsqueda de espacios para el intercambio y comercialización de productos es parte de una estrategia que se ha identificado en la literatura como una forma de adaptación de los indígenas a las condiciones de urbanización (Arcila, 2011), e integración a las economías de mercado; estas estrategias establecen ciertas tendencias en cuanto a la consolidación de redes alimentarias locales (Yagüe, 2013) que incluyan a la producción indígena y su articulación con canales de intercambio y comercio local (Eloy, 2008; Fontaine, 2002; Mora de Jaramillo, 2012; Peña-Venegas et al., 2009). Más allá de eso, según los resultados, los motivos de las personas por participar de estas ferias y mercados sugieren propósitos que proyectan sus actividades hacia otras actividades económicas que incluyan la transformación de productos destinados a nichos de mercados que se presentan como verdes ${ }^{6}$, justos, ecológicos ${ }^{7}$ y que estén dispuestos a pagar un precio por acceder a productos hechos por comunidades indígenas bajo ciertas condiciones.

Estas nuevas oportunidades de mercado a diferencia de las tradicionales economías extractivas, fijan el precio y el valor de cambio no solo por la cantidad de trabajo socialmente necesario, también por los costos de los productores por conservar los servicios ecosistémicos, la diversidad genética y el trabajo que implica conectar los emprendimientos asociativos de indígenas, grupos de mujeres y las instituciones que los apoyan. En este aspecto, los resultados sugieren una interesante perspectiva de las comunidades para alcanzar este tipo de mercados, en los cuales ya participan asociaciones como ASMUCOTAR.

Los cambios en la estructura social del indigenismo evidencian una estrategia de las comunidades para acceder a los beneficios de la modernidad (Gros, 2012), interpretando y reinventando el mundo desde una simbología que se asume como propia y que reconoce el otro como parte de una realidad más amplia. La creciente interculturalidad de las formas sociales del ser indígena, lleva implícito ese constante redescubrimiento de sus reivindicaciones por la tierra y la cultura(Gros, 2012). El mercado, como esfera inmersa en las relaciones sociales, y en este caso, a las etnicidades amazónicas, no es ajena a esta diversidad de interpretaciones del ser indígena, y más que representar una uniformización de las relaciones de producción como lo puede sugerir la teoría marxista sugiere una diversidad de formas de indigenizar los mercados.

Para Otero (2004) la relación clave entre comunidades indígenas y los grupos dominantes toma lugar a través de los mercados y no a través de la producción, en cualquiera de los casos, las relaciones étnicas al interior de relaciones asimétricas de producción o de mercado tienden a reforzar la identidad étnica, o a forzar al grupo étnico subordinado a la asimilación. Asícomomuchos teóricos de la línea de los estudios decoloniales se refieren ala uniformidad del ser en los valores del capitalismo y el mercado, en 
otro sentido también es posible dar cuenta de como se diversifican las interpretaciones y respuestas al capitalismo, respuestas que no lleven necesariamente a los conocimientos indígenas a su desaparición, ni a convertirse en objetos de consumo, ni fetiches culturales del capital,y que mas bien dan cuenta de un cierto proceso de indigenizacion del mercado, así como Sahlins da cuenta de un proceso de indigenización de la modernidad, como una identidad indígena que se adapta y responde a la modernidad, que desmiente la oposición entre tradición y cambio, costumbre y racionalidad, y aún más en el siglo XX entre tradición y desarrollo (Gros, 2012).

\section{Conclusiones}

El cambio en los modos de vida indígena de los pueblos del Trapecio Amazónico, ha llevado a mucha población indígena a una vida urbana, transformando sus formas tradicionales de intercambio basadas en la redistribución y la reciprocidad, por relaciones comerciales mediadas por dinero. Las interacciones de las economías de los pueblos indígenascon las economías de mercado, dan cuenta de una compleja adaptación que reinterpreta el lugar de las relaciones de reciprocidad con respecto a procesos más amplios como la pluriculturalidad y la economía globalizada.

Las economías indígenas basadas en sistema productivo de chagras $y$ en relaciones de reciprocidad pueden presentar formas novedosas de adaptación a los mercados locales, donde antes de hablar de mercados capitalistas podemos referirnos a procesos de construcción de mercados indígenas, inspirados en la famosa metáfora de Sahlins sobre la indigenización de la modernidad. Así, las formas económicas locales pueden verse como adaptaciones económicas de los pueblos indígenas a las relaciones capitalistas. Esta adaptación se da de manera compleja y no supone un reemplazo unidireccional de unas formas "propias" por otras "foráneas", sino deja ver diferentes respuestas en cuanto a su relación con estructuras económicas que se les imponen, y la forma como las economías locales interpreta y transforman ese esquema de valores. 


\section{Notas}

${ }^{1}$ Este artículo hace parte de la tesis de Maestría en Ciencias en Recursos Naturales y Desarrollo Rural del Colegio de la Frontera Sur, San Cristóbal de las Casas, México; y parte del grupo de investigación Valoración del Conocimiento Tradicional del Instituto Amazónico de Investigaciones Científicas Sinchi, Leticia, Colombia

${ }^{2}$ La estructura social que sustenta este modo de producción no solo se justifica en cuanto al acceso a los alimentos, sino es también un importante escenario de reproducción cultural, donde se transmiten importantes conocimientos sobre uso de plantas medicinales, ciclos de siembra, cosecha, limpieza, socala y tumba de la chagra. Cuando terminan las cosechas de las plantas de ciclo corto se deja descansar el suelo, permitiendo la sucesión secundaria y la producción de biomasa (Morán, 1993), en un proceso que va de chagra a bosque en un continuum dinámico (Rodríguez \& Van Der Hammen, 2011).

${ }^{3}$ En algunas malocas aún se hacen fiestas cuando en la chagra hay abundancia, por ejemplo en el cabildo Bora aprovechan cuando hay cosecha de piña con la cual preparan la caguana, una bebida de almidón de yuca con jugo de piña. En el cabildo Cocama hacen fiesta cuando es la cosecha de chontaduro (Bactris gasipaes).

${ }^{4} \mathrm{Al}$ respecto, el abuelo Teófilo Ceita dice: “cuando hay abundancia, no hay envidia, no estoy peleando porque el otro no me dio yuca, no me dio plátano, no me dio piña, no me dio la fariñita que él hizo, no estoy bravo con él, ni estoy hablando mal de él por eso, porque? Porque yo también tengo, no voy a robar de otro, porque yo tengo, eso es unidad, abundancia, el respeto. Por eso dice la palabra de la chagra, la chagra es para nosotros la vida, y porque es la vida, porque del fruto de la chagra somos esencia de ella, de ahí nacimos, de ahí nos formamos”(ASOAINTAM \& Sinchi, 2012).

${ }^{5}$ La gran mayoría de la pulpa de camu camu se lleva a restaurantes de Bogotá, un kilo de pulpa en Tarapacá vale 1,50 USD y rinde para 30 personas, en Bogotá se vende un vaso de jugo de camu camu en 3 USD.

${ }^{6}$ La economía verde es una aplicación de la economía neoclásica al manejo de los recursos naturales y los impactos generados por los seres humanos, que asigna valores económicos y precios a los recursos naturales, con el fin de que los daños y los impactos ambientales sean asumidos por los causantes como una aplicación del principio "el que contamina paga”, trabaja con flujos monetarios y financieros y asume el planeta como un sistema cerrado.

${ }^{7}$ La economía ecológica es un campo de investigación transdiciplinario que critica la visón de la Economía Ambiental o Economía Verde, trabaja con flujos de materia y energía y considera el planeta como un sistema abierto al ingreso de energía. 


\section{Bibliografía}

Acosta, L. E. (2013), Pueblos indígenas de la Amazonia e indicadores de bienestar humano en la encrucijada de la globalización?: estudio de caso Amazonia colombiana. Universidad del País Vasco, País Vasco.

Acosta, L. E., Perez, M., Juragaro, L. A., Nonokudo, H., Sanchez, G., Zafiama, A. M., Neikase, S. (2011), La chagra en La Chorrera: más que una producción de subsistencia, es una fuente de comunicación y alimento físico y espiritual, de los Hijos del tabaco, la coca y la yuca dulce. Instituto Amazónico de Investigaciones Cientificas, Sinchi. Ministerio de Ambiente y Desarrollo Sostenible. Asociación de Cabildos y Autoridades Tradicionales de La Chorrera, AZICATCH, Leticia, Amazonas. Retrieved from https:/ /www.siac.gov.co/documentos/DOC_Portal/DOC_Biodiversidad/ 110912_Libro_CHAGRAS_SINCHI_B.pdf

Arcila, O. (2011), La Amazonia colombiana urbanizada Un análisis de sus asentamientos humanos, Instituto Amazónico de Investigaciones Científicas, Sinchi, Bogotá, D.C.

ASOAINTAM, \& Sinchi, I. (2012), “La palabra de la gente de Uitiboc”, en S. Uruburu \& P. De La Cruz Nassar (Eds.), Encuentro realizado en el marco del proyecto "Incorporación del conocimiento tradicional asociado a la agrobiodiversidad en agroecosistemas colombianos”. 26 de julio de 2012. (p. 35). Tarapacá-Amazonas.: (No Publicado). Retrieved from http:/ /www.feriadelaschagras.blogspot.mx/2014/07/la-palabra-de-la-gente-deuitiboc.html

Castro, M. O. (2009), Dinámicas espaciales y temporales del componente demográfico de la región amazónica colombiana. Aspectos sociales para el desarrollo humano sostenible en la región amazónica colombiana.Ministerio de ambiente, vivineda y desarrollo territorial República de Colombia. Instituto Amazónico de Investigaciones Científica, Sinchi, Bogotá, D.C.

Davis, W. (2009),The Wayfinders: Why Ancient Wisdom Matters in the Modern World, ANANSI,Toronto

De La Cruz Nassar, P. E. (2015), Ferias de Chagras en la Amazonia colombiana, contribuciones a los conocimientos tradicionales, y al intercambio de productos de las asociaciones indígenas y de mujeres de Tarapacá. El Colegio de la Frontera Sur, San Cristóbal de las Casas.

De La Cruz, P. (2010), Módulos de Capacitación diseñados en administración de empresas, empresas solidarias y organización empresarial involucrando al SENA como institución que imparte dichas capacitaciones, Instituto Sinchi, Leticia.

De La Cruz, P. (2012),Producto 6. Contrato 018. Poyecto. Incorporación del Conocimiento Tradicional Asociado a la agrodiversidad en 
agroecosistemas colombianos, PNUD, GEF, MADS, Sinchi. Leticia, Amazonas.

De La Cruz, P. (2013),Producto 1 y 2. Contrato $N^{\circ}$ 17. Proyecto: Incorporación del Conocimiento Tradicional Asociado a la Agrobiodiversidad en Agroecosistemas colombianos, PNUD, GEF, MADS, Sinchi. Leticia, Amazonas.

de Robert, P., \& van Helthem, L. (2008),’L’heure du tacacá. Consommation et valorisation d'aliments traditionnels amazoniens en zone urbaine (Brésil)", Anthropology of Food S4 | May 2008?: Modèles Alimentaires et Recompositions Sociales En Amérique Latin, S4, p. 1-15. Retrieved from http://aof.revues.org/3533

Eloy, L. (2008),’Diversité alimentaire et urbanisation Le rôle des mobilités circulaires des Amérindiens dans le Nord-Ouest Amazonien”. En C.-E. de Suremain \& E. Katz (Eds.), Anthropology of food. Modèles alimentaires et recompositions sociales en Amérique latine. Retrieved from http:// aof.revues.org/2882

Eloy, L., \& Le Tourneau, F. M. (2009),’L’urbanisation provoque-t-elle la déforestation en Amazonie?? Innovations territoriales et agricoles dans le nord-ouest amazonien (Brésil)”,Annales de Géographie, 3(607), p.204227. http://doi.org/DOI?: 10.3917/ag.667.0204

Fontaine, L. (2002), La monnaie, une modalité d'échange parmi d'autres chez les Indiens yucuna d'Amazonie colombienne, (171-188), 1-13.

Freire, G. N. (2014),’Indigenous Shifting Cultivation and the New Amazonia?: A Piaroa Example of Economic Articulation”,Human Ecology, 35(6), p.681-696. http://doi.org/10.1007/sl

Gasché, J. (2010),’De hablar de educación intercultural a hacerla”,Mundo Amazonico, 1, 111-134. http://doi.org/10.5113/ma.1.9414

Giraldo, O. F. (2013), Hacia una ontología de la Agri-Cultura en perspectiva del pensamiento ambiental, Polis, Revista Latinoamericana, vol.12, n³4, p. 95-115.

Graeber, D. (2001), Toward an Anthropological Theory of Value. The False Coin of Our Own Dreams, PALGRAVE, New York.

Graeber, D. (2012),En Deuda. Una Historia Alternativa de la Economía, Ariel, Madrid.

Gros, C. (2012),Políticas de la etnicidad?: identidad, Estado y modernidad, Instituto Colombiano de Antropología e Historia (ICANH), Bogotá.

Gudeman, S. (2001), The Anthropology of Economy. Community, Market, 
and Culture (1st ed.). Blackwell. http://doi.org/10.1146/ annurev.an.34.082905.100003

Hernández, M. S., De La Cruz, P., Acosta, L. E., Ahuanari, A., Polanía, D., \& Borraez, F. (2010), “Organización social para el aprovechamiento sostenible del camu-camu (Myrciaria dubia (Kunth) McVaugh)”, en Tarapacá, departamento del Amazonas, Colombia. Instituto Amazónico de Investigaciones Cientificas, Sinchi. Ministerio de Ambiente, Vivienda y Desarrollo Territorial. ASMUCOTAR. ASOMATA. ECOFONDO, Bogotá. http:// doi.org/10.1533/9780857092762.352

Mora de Jaramillo, Y. (2012),Alimentación y cultura en el Amazonas (2nd ed.), Ministerio de Cultura, Bogotá.

Morán, E. F. (1993),La Ecologia Humana de los Pueblos de la Amazonia, Fondo de Cultura Económica, México, D. F.

Nash, M. (1967), "Current Anthropology, Primitive and Peasant Economic Systems”, enThe University of the Chicago Press, 8(3), p.244-250. Retrieved from http://www.jstor.org/stable/2740214

Otero, G. (2004), “Global Economy, Local Politics: Indigenous Struggles, Civil Society and Democracy”,Canadian Journal of Political Science / Revue Canadienne de Science Politique, 37(2), p.325-346. Retrieved from http:// www.jstor.org/stable/25165644 .

Peña-Venegas, C., Valderrama, A., Acosta, L. E., \& Pérez, M. (2009),Seguridad alimentaria en comunidades indígenas del Amazonas: ayer y hoy, Instituto Amazónico de Investigaciones Cientificas, Sinchi. Ministerio de Ambiente, Vivienda y Desarrollo Territorial, Bogotá.

Pinton, F. (2003), "Savoirs traditionnels et territoires de la biodiversité en Amazonie brésilienne”, Revue Internationale Des Sciences Sociales, 178(4), 667. http://doi.org/10.3917/riss.178.0667

Polanyi, K. (1989), La gran transformación. Critica del liberalismo económico, La Piqueta, Madrid.

Rincón, H. (2005), “Tarapacá: Un asentamiento producto de la presencia peruana en la Amazonía Colombiana”,Maguaré. Revista Del Departamento de Antropología. Facultad de Ciencias Humanas. Universidad Nacional de Colombia., (19), p.133-145.

Rodríguez, C., \& Van Der Hammen, M. C. (2011), “El bosque intervenido: conservación en territorios indígenas de la amazonia colombiana”, Revista Colombia Amazónica., (4), p.27-36.

Sahlins, M. (1983),Economía de la Edad de Piedra, Akal, Madrid. 
Sahlins, M. (1999),’What is anthropological enlightment? Some lessons of the twentieth tentury”, Annual Review of Anthropology, 28(1), i-xxiii. http:/ /doi.org/10.1146/annurev.anthro.28.1.0

Siegal, B. (1965), “Economic Anthropology”,Biennial Review of Anthropology, 4, p.121-138. Retrieved from http://www.jstor.org/stable/ 2949182 .

Trujillo Osorio, C. (2008),Selva y Mercado: Exploración cuantitativa de los ingresos monetarios en hogares indígenas, Universidad Nacional de Colombia, Leticia.

Yagüe, B. (2013),Haciendo comestible la ciudad?: Los indígenas urbanos de Leticia y sus redes desde la Soberanía Alimentaria. Universidad Nacional de Colombia, Leticia. Retrieved from http://www.bdigital.unal.edu.co/ 9570/

Zárate Botía, C. G. (2001),Extracción de quina: la configuración del espacio andino - amazónico de fines del siglo XIX, Universidad Nacional de Colombia, Leticia. http://doi.org/3722

Recibido: 12.09.16

Aceptado: 01.12.16 